\title{
ECODINÂMICA APLICADA À CONFECÇÃO DE CARTA DE FRAGILIDADE AMBIENTAL PARA INSTALAÇÃO DE ATERRO SANITÁRIO
}

\author{
Rodrigo Coladello de OLIVEIRA \\ Marcos Norberto BOIN ${ }^{2}$ \\ Munir Jorge $\mathrm{FELICCIO}^{3}$
}

\section{Resumo}

A Política Nacional de Resíduos Sólidos - PNRS (Lei 12.305/2010) previa o encerramento dos lixões e aterros controlados até agosto de 2014, contudo, em virtude da não adesão da grande maioria dos municípios brasileiros, o prazo foi prorrogado por mais 4 (quatro) anos. Com o objetivo de auxiliar os municípios no processo de escolha de área para aterro sanitário, o presente trabalho aplica os preceitos da teoria da ecodinâmica dos ambientes naturais na determinação de locais de fragilidade ambiental e, consequentemente, inadequados à instalação de depósitos de resíduos. A teoria da ecodinâmica apresentou-se demasiadamente relevante durante o processo de escolha de área, tendo em vista sua abordagem interdisciplinar, que considera os aspectos geológicos, pedológicos, hidrogeomorfológicos e climáticos.

Palavras-chave: Ecodinâmica. Resíduos Sólidos. Paisagem. Aterro Sanitário. Fragilidade Ambiental.

\section{Abstract}

\section{Ecodynamic applied to making environmental weakness maps for landfill site installation}

The National Solid Waste Policy - PNRS (Law 12.305 / 2010) predicted the closure of dumps and controlled landfills until August 2014, however, due to the non-adherence of the great majority of Brazilian municipalities, the deadline was extended by four (4) more years. In order to assist municipalities in the process of choosing the area for the landfill site, this paper applies the precepts of ecodynamic theory of natural environments in determining environmental fragility locals and, therefore, unsuitable for the installation of waste sites. The ecodynamic theory proved to be very important during the process of choosing the area, given its interdisciplinary approach, which considers the geological, soil, hydrogeomorphological and climatic features. fragility.

Key words: Ecodynamic. Solid waste. Landscape. Landfill site. Environmental

\footnotetext{
1 Professor Mestre do Centro Universitário Toledo - Presidente Prudente - SP. E-mail: rodcoladello@hotmail.com

2 Professor Doutor da Universidade Federal da Grande Dourados - MS. E-mail: boinmar@hotmail.com

3 Professor Doutor da Universidade do Oeste Paulista - Presidente Prudente - SP. E-mail: munir@unoeste.br
} 


\section{INTRODUÇÃO}

O estudo da ecodinâmica dos ambientes naturais de Tricart (1977) possui estreita relação com o modo de análise integrada da paisagem, tão preconizada por diversos autores (MATEO-RODRIGUEZ, 2004; LEAL, 1995; ROSS, 1994, AMARAL; ROSS, 2009) que trabalham com a temática voltada à geografia e à geografia física, visto que tal análise possui uma abordagem sistêmica do ambiente de estudo. Assim, a ecodinâmica dos ambientes é classificada conforme a intensidade dos processos atuantes, quer seja de origem antrópica quer seja natural, e são divididas em meios estáveis, intergrades (transição) e fortemente instáveis.

Nos meios estáveis, os processos de evolução do modelado ocorrem lentamente e são de difícil percepção. No entanto, a pedogênese prevalece sobre a morfogênese, visto que os estágios destes ambientes são considerados climáxicos e a vegetação existente é capaz de manter a estabilidade morfogenética através da fitoestabilidade. Consequentemente, a dissecação do relevo nestes ambientes tornase moderada e as vertentes, conservadas (TRICART, 1977).

Em meios intergrades, também denominados como meios de transição, a principal característica é a transição gradual entre os meios estáveis e instáveis, onde existem interferências constantes no balanço da pedogênese e morfogênese. Estes meios são considerados susceptíveis a amplificação e podem passar rapidamente do estado estável para o fortemente instável.

Ainda segundo Tricart (1977), nos meios fortemente instáveis, prevalecem as ações da morfogênese na dinâmica do modelado e a elevada dissecação, devido à ocorrência nula ou negativa do balanço pedogenético. Geralmente, esse fato está intimamente relacionado com causas naturais, como por exemplo, as ações das intempéries e os efeitos do tectonismo, porém, potencializado pelas atividades antrópicas.

Diante do exposto, a análise proposta pela ecodinâmica contribui positivamente para estudos com o objetivo de sintetizar as características da paisagem em unidades homogêneas, zoneamentos, diagnósticos ambientais e promover o planejamento ambiental, inclusive, no que diz respeito à escolha de área para instalação de aterro sanitário, destacando os recursos geológico-geomorfológicos do substrato que dá sustentação á paisagem.

Baseando-se nas possíveis adaptações da ecodinâmica supracitada, Ross (1994) apresenta uma análise empírica da fragilidade dos ambientes naturais antropizados, orientando-se principalmente pelos conceitos de Tricart (1977). Desta forma, Ross (1994) propõe outra denominação para as unidades estáveis e instáveis oriundas de sua adaptação, são elas unidades ecodinâmicas de instabilidade potencial e unidades ecodinâmicas de instabilidade emergente, respectivamente.

Tendo em vista a positividade nos resultados de tal análise empírica, Amaral e Ross (2009) aplicaram esses novos conceitos, acrescidos à ecodinâmica, para um estudo de análise da fragilidade ambiental e avaliação de áreas suscetíveis à degradação, para então subsidiarem medidas que promovam o planejamento do uso e ocupação da terra. O resultado desta análise compõe uma matriz de correlação e a confecção da carta de unidades ecodinâmicas de instabilidade potencial e emergente.

A flexibilidade da aplicação da análise proposta por Ross (1994), posteriormente aplicada e cartografada por Amaral e Ross (2009), e a abordagem sistêmica que o método apresenta, permitiu ao presente artigo aplicar o método dos autores supracitados, porém, voltado à delimitação de unidades ecodinâmicas na análise da fragilidade ambiental, na escolha de área para aterro sanitário.

Assim, este trabalho baseia-se na problemática da disposição final de resíduos sólidos, sobre a qual a Política Nacional de Resíduos Sólidos (PNRS), instituída pela Lei 
12.305/2010, previa a extinção dos aterros controlados e de lixões até agosto de 2014, contudo, recentemente foi prorrogada por mais quatro anos, conforme a Medida Provisória (MP) 651/2014.

Além disso, o temário resíduo sólido insere-se em um intenso debate desde a aprovação da PNRS, em 2010. No que tange ao contexto do município em estudo e da Unidade de Gerenciamento de Recursos Hídricos-22 (UGRHI-22), observa-se que a disposição dos resíduos sólidos urbanos ainda permanecem majoritariamente em aterros controlados e vazadouros à céu aberto (exceto Presidente Venceslau), métodos dos quais possuem insuficiência comprovada por Oliveira (2002), Boscov (2012), Oliveira $(2012 ; 2014 ; 2015)$, os quais elencam os inúmeros impactos negativos dessas atividades em esferas ambientais, sociais e econômicas.

Portanto, em função da inconsistência dos atuais métodos de destinação final dos resíduos sólidos urbanos, o presente trabalho tem como objetivo adequar a metodologia de análise empírica de Ross (1994) e Amaral e Ross (2009) para auxiliar no processo de escolha de área para aterro sanitário no município de Anhumas, além de contribuir para o planejamento ambiental do município através da confecção da carta de fragilidade ambiental.

\section{ÁREA DE ESTUDO}

No que se refere às características do objeto de estudo, este possui área total de aproximadamente $320 \mathrm{~km}^{2}$ e está situado no oeste do estado de São Paulo, cujas coordenadas do ponto central da cidade são: $22^{\circ} 17^{\prime} 45^{\prime \prime S}$ (Latitudinais) e 510 23' $08 \mathrm{~W}$ (Longitudinais).

Localizado sobre o Planalto Ocidental Paulista, o município de Anhumas, apresenta relevo de colinas assentado sobre o substrato rochoso arenoso da bacia sedimentar do Paraná, de idade cretácea, representada pela Formação Adamantina, unidades de mapeamento $\mathrm{Ka}_{\mathrm{I}}, \mathrm{KA}_{\mathrm{IV}}$ e $\mathrm{Ka}_{\mathrm{V}}$ (ALMEIDA et al, 1980) e sedimentos quaternário inconsolados, fluviais de calha ou de terraços.

Conforme a EMBRAPA (1999), as classes de solos existentes são Latossolo Vermelho-Escuro, Argissolo Vermelho-Amarelo, Neossolo Litólico e Neossolos Quartzarênicos, cujas texturas apresentam-se como média ou arenosa/média.

O clima do município caracteriza-se por situar-se em zona de transição climática, sendo compartilhado pelos sistemas atmosféricos intertropicais e extratropicais, que promovem o conflito entre as massas Tropical Atlântica e Tropical Continental, massa Polar Atlântica e, ainda, participação esporádica de massa Equatorial Continental (BOIN, 2000). Este clima é representado por uma estação chuvosa e outra seca, chovendo em média $1300 \mathrm{~mm}$ por ano e uma temperatura média de 23,9 oC. A vegetação primitiva do município é composta pelo bioma da Mata Atlântica, representada pelas fisionomias Floresta Estacional Semidecidual ${ }_{\perp}$ com enclaves de tensão ecológicas caracterizados como cerrado.

\section{METODOLOGIA}

Para o desenvolvimento do presente trabalho, aplicou-se o modelo de mapeamento de unidades ecodinâmicas proposto por Ross (1994) e Amaral e Ross (2009), que por sua vez, tiveram como base as concepções de ecodinâmica e ecossistema, definidas por Tricart (1977) na determinação das unidades ecodinâmicas 
de instabilidade potencial (estável) e de instabilidade emergente (instável), classificando-as através de seus graus de fragilidade, conforme evidenciado no quadro 1.

\section{Quadro 1 - Relação entre os conceitos de ambientes naturais e antropizados definidos por ROSS (1994) e TRICART (1977)}

\begin{tabular}{|c|c|c|c|}
\hline \multirow{2}{*}{ AUTORES } & \multirow{2}{*}{$\begin{array}{c}\text { PROPOSTA } \\
\text { METODOLÓGICA }\end{array}$} & \multicolumn{2}{|c|}{ CONCEITUAÇÃO } \\
\cline { 3 - 4 } & AMBIENTES NATURAIS & $\begin{array}{c}\text { AMBIENTES } \\
\text { ANTROPIZADOS }\end{array}$ \\
\hline $\begin{array}{c}\text { TRICART, } \\
1977\end{array}$ & Ecodinâmica & Unidades estáveis & Unidades instáveis \\
\hline Ross, 1994 & $\begin{array}{c}\text { Fragilidade } \\
\text { ambiental }\end{array}$ & $\begin{array}{c}\text { Unidades ecodinâmicasde } \\
\text { instabilidade potencial }\end{array}$ & $\begin{array}{c}\text { Unidades ecodinâmicas de } \\
\text { instabilidade emergente }\end{array}$ \\
\hline
\end{tabular}

Fonte: Os autores, 2015.

Assim, compreende-se no presente trabalho que as unidades ecodinâmicas de instabilidade potencial são aquelas em que o equilíbrio dinâmico encontra-se no seu estado natural, mas que há uma instabilidade potencial contida, devido à possível intervenção antrópica. Já as unidades ecodinâmicas de instabilidade emergente são apresentadas como ambientes naturais, os quais, em determinada ocasião, foram intensamente alterados por atividades antrópicas de vários gêneros.

Para chegar a essas categorias, o método de análise de fragilidade considera os elementos do meio físico e de uso da terra para obter a classificação das unidades ecodinâmicas, sendo necessário realizar um levantamento dos constituintes da paisagem para representar o grau de fragilidade dos ambientes.

Cabe destacar ainda que alguns autores, como Zuquette; Pejon; Sineli (1994), Leite (1995), Leite; Zuquette (1996), Tressoldi; Consoni (1998), Montaño et al. (2012) e Boscov (2012), utilizam-se de elementos semelhantes da paisagem para a escolha de locais potenciais para instalação de aterro sanitário. A distinção entre eles encontra-se no método de análise dos elementos, para os quais são utilizados valores tabelados e que muitas vezes dificultam a universalização de sua aplicação.

Para isso, necessita-se analisar os condicionantes da paisagem de modo integrado, para que possamos identificar a fragilidade natural de cada meio, assim como outrora realizado por Nunes (2002) na escolha de área para aterro sanitário no município de Presidente Prudente - SP.

Nesse sentido, o presente trabalho aplicou a teoria ecodinâmica na análise da fragilidade ambiental, estabelecendo critérios de observação aos fatores do meio físico e de uso da terra, os quais compõem o quadro 2, a seguir.

Outro fator de importância na análise da fragilidade ambiental a ser destacado nesta abordagem é a geologia, a qual apresenta através de suas características litológicas e estruturais uma maior predisposição a infiltração dos percolados originados da decomposição e alteração dos resíduos sólidos. 


\section{Quadro 2 - Fatores e elementos de análise para determinação da fragilidade ambiental}

\begin{tabular}{|c|l|}
\hline FATORES DE ANÁLISE & \multicolumn{1}{|c|}{ ELEMENTOS } \\
\hline $\begin{array}{c}\text { Uso da terra / cobertura } \\
\text { vegetal }\end{array}$ & Densidade da cobertura vegetal \\
\hline Relevo & $\begin{array}{l}\text { Compartimentação de relevo } \\
\text { Índice de declividade }\end{array}$ \\
\hline Solos & $\begin{array}{l}\text { Textura (análise granulométrica) } \\
\text { Profundidade / espessura dos horizontes superficiais e subsuperficiais } \\
\text { Permeabilidade }\end{array}$ \\
\hline Clima & $\begin{array}{l}\text { Distribuição anual e intensidade da pluviometria } \\
\text { Temperatura } \\
\text { Direção dos ventos }\end{array}$ \\
\hline
\end{tabular}

Fonte: Os autores, 2015.

As fácies litológicas (arenosa, areno-siltosa e areno-silto-argilosa) definem a presença de lençóis freáticos locais e regionais, apresentando-se em diferentes profundidades e distanciamento dos corpos hídricos. A presença dos lençóis freáticos geralmente é evidenciada nos solos em função da umidade contida nestes locais, sendo que através de análises de geoprocessamento e trabalhos de campo, podem ser caracterizados e identificados como zonas de fragilidade ambiental pela proximidade com os recursos hídricos. Tratam-se, então, de locais restritos à instalação de atividades potencialmente poluidoras, a exemplo dos aterros sanitários.

Tendo em vista tal situação, estabeleceram-se os seguintes níveis de fragilidade às unidades litológicas levantadas neste estudo (Quadro 3).

\section{Quadro 3 - Classes de fragilidade de acordo com as unidades litológicas de Almeida et al. (1980) e ocorrência de recursos hídricos na área de estudo}

\begin{tabular}{|c|c|}
\hline $\begin{array}{l}\text { GRAUS DE } \\
\text { FRAGILIDADE }\end{array}$ & $\begin{array}{c}\text { UNIDADES LITOLÓGICAS } \\
\text { (OCORRÊNCIAS NA ÁREA DE ESTUDO) }\end{array}$ \\
\hline 1 - Muito baixo & (Sem ocorrência) \\
\hline 2 - Baixo & $\begin{array}{l}\text { Formação Adamantina, unidade de mapeamento } \mathrm{Ka}_{1} \text {, com arenitos finos a } \\
\text { muito finos, siltitos arenosos, arenitos argilitos, subordinadamente arenitos } \\
\text { com granulação média quartzosos, localmente arcoseanos. Presença apenas de } \\
\text { freáticos regionais }\end{array}$ \\
\hline 3 - Médio & $\begin{array}{l}\text { Formação Adamantina, unidade de mapeamento } \mathrm{Ka}_{v} \text {, arenitos finos a muito } \\
\text { finos, quartzosos, com frequentes intercalações de argilitos e siltitos, formando } \\
\text { bancos pouco espessos. Localmente arenitos com pelotas de argila. } \\
\text { Frequentemente presença de cimentação carbonática, mais raramente, } \\
\text { nódulos. Presença de freáticos regionais e lençóis suspensos (freático local) }\end{array}$ \\
\hline 4 - Alto & $\begin{array}{l}\text { Formação Adamantina, unidade de mapeamento } \mathrm{Ka}_{\mathrm{IV}} \text {, arenitos finos a muito } \\
\text { finos, quartzosos, com frequentes intercalações de argilitos e siltitos, formando } \\
\text { bancos pouco espessos. Localmente arenitos finos, com pelotas de argila. } \\
\text { Presença moderada de cimentação carbonática. Presença de freáticos regionais } \\
\text { e maior ocorrência de lençóis suspensos (freático local) }\end{array}$ \\
\hline 5 - Muito alto & $\begin{array}{l}\text { Sedimentos em geral, incluindo areias inconsolidadas de granulação variável, } \\
\text { argilas e cascalheiras fluviais subordinadamente, em depósitos de calha e/ou } \\
\text { terraços. Presença do recurso hídrico superficial }\end{array}$ \\
\hline
\end{tabular}

Fonte: Os autores, 2015. 
Todos os fatores de análise supracitados receberam seus respectivos graus de fragilidade e foram hierarquizados em quatro categorias - com exceção daquele relacionado com as unidades litológicas, pois como apontado anteriormente, as mesmas se fazem refletir nas classes de solo: muito baixo, baixo, médio, alto e muito alto. 0 somatório dos graus corresponde à associação de todos os fatores analisados, sendo o uso da terra/cobertura vegetal (Quadro 4) o preponderante nesta análise para determinar a classificação das unidades ecodinâmicas.

\section{Quadro 4 - Graus de proteção do solo na área de estudo, de acordo com o uso da terra, levantados pelo autor sobre ortofoto de detalhe da EMPLASA (2011)}

\begin{tabular}{|l|l|}
\hline \multicolumn{1}{|c|}{$\begin{array}{c}\text { GRAUS DE } \\
\text { PROTEÇÃO }\end{array}$} & \multicolumn{1}{c|}{$\begin{array}{c}\text { TIPOS DE USO DA TERRA / COBERTURA VEGETAL } \\
\text { (OCORRÊNCIAS NA ÁREA DE ESTUDO) }\end{array}$} \\
\hline 1 - Muito alto & Florestas / matas naturais \\
\hline 2 - Alto & Capoeira / vegetação palustre / pousio \\
\hline 3 - Médio & $\begin{array}{l}\text { Silvicultura (eucalipto). Cultura permanente (banana, } \\
\text { café, laranja, limão, etc.). Cultivo de cana de açúcar }\end{array}$ \\
\hline 4 - Baixo & Cultura temporária (trigo, soja, milho, feijão, batata, etc.) \\
\hline $\begin{array}{l}\text { 5- Muito baixo a } \\
\text { nulo }\end{array}$ & $\begin{array}{l}\text { Outros (pastagem, solo em processo de preparo para o } \\
\text { plantio, etc.) }\end{array}$ \\
\hline
\end{tabular}

Fonte: Os autores, 2015.

\section{Quadro 5 - Classes de fragilidade de acordo com os tipos de compartimentações geomorfológicas (Adaptadas de IPT, 1981b) e predominância de vertentes associadas às declividades (obtidas pela imagem SRTM - Shuttle Radar Topography Mission, 2010) na área de estudo}

\begin{tabular}{|l|l|}
\hline $\begin{array}{c}\text { GRAUS DE } \\
\text { FRAGILIDADE }\end{array}$ & \multicolumn{1}{|c|}{$\begin{array}{c}\text { TIPOS DE RELEVO / GEOLOGIA E DECLIVIDADE } \\
\text { (OCORREENCIAS NA ÁREA DE ESTUDO) }\end{array}$} \\
\hline 1 - Muito baixo & $\begin{array}{l}\text { Topos planos associado à unidade de mapeamento KaI - vales } \\
\text { abertos, padrão de drenagem subdendrítico de baixa densidade e } \\
\text { planícies aluviais restritas (0 - 5\% de declividade) }\end{array}$ \\
\hline 2 - Baixo & $\begin{array}{l}\text { Topos convexos associados à unidade de mapeamento KaIV e KaV, } \\
\text { com topos aplainados subordinados e eventuais colos topográficos ( 2 } \\
-10 \% \text { de declividade) }\end{array}$ \\
\hline 3 - Médio & $\begin{array}{l}\text { Vertentes convexas retilíneas sem a ocorrência de lençóis de meia } \\
\text { encosta associadas à unidade KaI, à baixa densidade de drenagem } \\
\text { dendrítica sem a ocorrência de processos de erosão ( 5 - 10\% de } \\
\text { declividade) }\end{array}$ \\
\hline $4-$ Alto & $\begin{array}{l}\text { Vertentes convexas, côncavas e retilíneas associadas à unidade KaIV e } \\
\text { KaV, com presença de lençóis de meia encosta e feições erosivas } \\
\text { decorrentes de atividades antrópicas. Notórias rupturas de declive } \\
\text { (>10\% de declividade) }\end{array}$ \\
\hline 5 - Muito alto & $\begin{array}{l}\text { Planícies fluviais, situadas junto aos principais cursos d'água e leques } \\
\text { aluviais, atribuem formatos alveolares em determinados setores (0 - } \\
5 \% \text { de declividade) }\end{array}$ \\
\hline
\end{tabular}

Fonte: Os autores, 2015. 
Associados também aos diferentes tipos de relevos, a ocorrência dos solos submetidos a processos de hidromorfismo - sejam localizados em planícies fluviais; fundos de vale, constituindo freáticos regionais; ou em meia encosta - receberam o grau de fragilidade muito alto, por constituírem peculiaridades importantes para esta análise: possibilidade de contaminação dos recursos hídricos.

\section{Quadro 6 - Classes de fragilidade do solo, em associação com as unidades litológicas presentes na área de estudo. Adaptado da classificação de solos da EMBRAPA (1999)}

\begin{tabular}{|c|c|}
\hline $\begin{array}{c}\text { GRAUS DE } \\
\text { FRAGILIDADE }\end{array}$ & TIPOS DE SOLOS (OCORRÊNCIAS NA ÁREA DE ESTUDO) \\
\hline 1 - Muito baixo & $\begin{array}{l}\text { Latossolo vermelho-escuro (LEa29), álico, textura média + Argissolo } \\
\text { vermelho-amarelo eutrófico, textura arenosa/média e média + Argissolo } \\
\text { vermelho-escuro eutrófico e distrófico, textura arenosa/média. } \\
\text { Ocorrência na unidade de mapeamento } \mathrm{Ka}_{\mathrm{I}} \mathrm{da} \text { Formação Adamantina }\end{array}$ \\
\hline 2 - Baixo & $\begin{array}{l}\text { Argissolo vermelho-amarelo ( } \mathrm{PVe} 9) \text {, eutrófico, textura arenosa média e } \\
\text { média. Ocorrência predominantemente na unidade de mapeamento Kav } \\
\text { e parte da unidade de mapeamento } \mathrm{Ka}_{\mathrm{IV}} \text { da Formação Adamantina }\end{array}$ \\
\hline 3 - Médio & $\begin{array}{l}\text { Argissolo vermelho-amarelo (PVe8), eutrófico, abruptco, textura } \\
\text { arenosa/média + Argissolo vermelho-amarelo, eutrófico, textura } \\
\text { arenosa/média + surgimento de concreções ferruginosas. Argissolo } \\
\text { vermelho-amarelo (PVe6), textura arenosa/média e média + Argissolo } \\
\text { vermelho-amarelo abruptco, textura arenosa/média + surgimento de } \\
\text { concreções ferruginosas. Ocorrência predominante na unidade de } \\
\text { mapeamento KaIv e subordinadamente na unidade de mapeamento Kav } \\
\text { da Formação Adamantina }\end{array}$ \\
\hline 4 - Alto & $\begin{array}{l}\text { NeossoloLitólico, distrófico, fragmentário, horizonte A tênue e transição } \\
\text { direta para o substrato rochoso em processo de intemperização. } \\
\text { Ocorrência tanto na unidade de mapeamento } \mathrm{Ka}_{\mathrm{IV}} \text {, quanto na unidade } \\
\text { de mapeamento } \mathrm{Ka} \text { e, esporadicamente, na unidade de mapeamento } \\
\mathrm{Ka}_{\mathrm{I}} \text { da Formação Adamantina }\end{array}$ \\
\hline 5 - Muito alto & $\begin{array}{l}\text { Areias quartzosas álicas (AQa5) + associação complexa de areias } \\
\text { quartzosas hidromórficasálicas + Glei pouco húmico distrófico e } \\
\text { eutrófico, textura argilosa e muito argilosa }+ \text { Glei húmico distrófico e } \\
\text { eutrófico textura argilosa e muito argilosa }+ \text { Planossoloálico, textura } \\
\text { arenosa/média e arenosa/argilosa }+ \text { solos orgânicos álicos, textura } \\
\text { indiscriminada (planície }- \text { depósitos de calha e/ou terraços fluviais) } \\
\text { NeossoloLitólico submetidos ao hidromorfismo }\end{array}$ \\
\hline
\end{tabular}

Fonte: Os autores, 2015.

Os elementos climáticos foram considerados de modo uniforme em toda a área, visto que conforme a classificação climática proposta por Boin (2000) para o oeste paulista, atribui-se ao município de Anhumas a categoria BIVm $\alpha$, sendo suas características e grau de fragilidade observadas no quadro 7, a seguir. 


\section{Quadro 7 - Níveis de comportamento dos elementos climáticos na área de estudo}

\begin{tabular}{|l|l|}
\hline \multicolumn{1}{|c|}{$\begin{array}{c}\text { GRAUS DE } \\
\text { FRAGILIDADE }\end{array}$} & \multicolumn{1}{c|}{$\begin{array}{c}\text { CARACTERÍSTICAS DOS ELEMENTOS CLIMÁTICOS } \\
\text { (OCORRÊNCIAS NA ÁREA DE ESTUDO) }\end{array}$} \\
\hline 1 - Muito baixo & (Sem ocorrência) \\
\hline 2 - Baixo & (Sem ocorrência) \\
\hline 3 - Médio & $\begin{array}{l}\text { Situação pluviométrica com distribuição anual desigual: com período } \\
\text { seco entre } 2 \text { e } 3 \text { meses, no inverno (junho, julho e agosto), e no } \\
\text { verão, com maior intensidade (dezembro, janeiro e fevereiro). } \\
\text { Média anual em torno de 1300 mm/a } \\
\text { Temperatura com grande variabilidade anual e média de 23,9² } \\
\text { Ventos predominantes, de leste e dos quadrantes NE e SE }\end{array}$ \\
\hline $4-$ Alto & (Sem ocorrência) \\
\hline 5 - Muito alto & (Sem ocorrência) \\
\hline
\end{tabular}

Fonte: Os autores, 2015.

A composição final será, então, apresentada em formato de carta síntese, por meio da integração sistemática de todos os elementos apontados anteriormente, sendo que o primeiro dígito da associação numérica representa o grau de proteção dos solos pelo uso da terra, variando de mais protetora a menos protetora (Quadro 4); o segundo, a compartimentação do relevo e predominância de vertentes associadas às declividades (Quadro 5); o terceiro, a suscetibilidade à infiltração dos percolados relacionado aos tipos de solo, do menos susceptível ao mais susceptível (Quadro 6); e, finalmente, o quarto dígito, ao tipo de comportamento dos elementos climáticos (Quadro 7).

No que se refere à elaboração da carta de declividade utilizada para auxiliar a categorização dos níveis de fragilidade da área em estudo, seguiu-se uma metodologia de geoprocessamento disponibilizada pela Comunidade Virtual Spring e elaborado por Alves (2008) através de dados da imagem de radar da SRTM (Shuttle Radar Topography Mission). As imagens foram adquiridas gratuitamente na plataforma "Topodata", disponível no site do Instituto Nacional de Pesquisas Espaciais em formato GEOTIFF (16 bits), resolução espacial interpolada de 90 metros para 30 metros e sistema de coordenadas Datum WGS-84. Os intervalos de declividade seguiram a ordem de $0-2 \%, 2-5 \%, 5-8 \%, 8-10 \%, 10-15 \%, 15-20$ e $20-23 \%$ e obedecendo aos valores mínimos e máximos identificados na análise geoestatísticas. Após inserir todos os intervalos e realizar o fatiamento, gerou-se então, uma matriz com os elementos de declividade inseridos em um plano de informação de categoria temático.

A categorização foi efetuada a partir da interpretação de fotografias aéreas ortorretificadas $\_$produzidas pela EMPLASA no ano de 2011, com resolução espacial de um metro, na faixa do visível, possibilitando identificar os "alvos" feições ou indicações de fragilidade ambiental através de chaves de interpretação. Tais interpretações foram reambuladas com trabalhos de campo e, concomitantemente, a elaboração da carta de uso da terra.

Os vetores de classificação foram obtidos pelo SIG - Sistema de Informação Geográfica Spring através de ferramenta de vetorização, exceto a carta de declividade que foi aplicada técnicas de geoprocessamento conforme descrito anteriormente. Todos os dados foram exportados para o programa Corel Draw ${ }^{\circledR}$, classificando-as pelo método da sobreposição "dois a dois", conforme SANTOS (2004. p.136). 
O método da sobreposição de Santos (2004) confere uma abordagem qualitativa ao identificar os condicionantes geoambientais de interesse no estudo, servindo de base para confecção de mapas temáticos, que, quando sobrepostos por sucessivos cruzamentos binários seguidos de um passo a passo, compor-se-ão mapas intermediários até finalmente gerar a carta síntese onde representa a integração de todos os condicionantes. Tal integração pode ser realizada automaticamente através de sistemas de informações geográficas - SIG ou manualmente em outros softwares capazes de reconhecer objetos vetoriais.

\section{RESULTADOS}

Como resultado da integração, ao correlacionar em uma matriz as compartimentações do relevo e os tipos de solos, visando identificar unidades ecodinâmicas de instabilidade potencial, chegou-se ao conjunto de combinações numéricas que representam os diferentes graus de fragilidade (Quadro 8), os quais variam de "muito baixo" a "muito alto". A constante considerada nesta matriz foi: cobertura vegetal = grau de proteção (1) - elemento preponderante para classificação das unidades de instabilidade potencial.

\section{Quadro 8 - Matriz de correlação entre relevo e solos para classificação das unidades ecodinâmicas de instabilidade potencial}

\begin{tabular}{|c|c|c|c|c|c|}
\hline \multicolumn{6}{|c|}{$\begin{array}{c}\text { MATRIZ DE CORRELAÇÃO RELEVO X SOLOS PARA } \\
\text { UNIDADES ECODINÂMICAS DE INSTABILIDADE POTENCIAL (ESTÁVEIS) } \\
\text { Constantes - Fator Uso da Terra / Cobertura vegetal = grau de proteção (1) }\end{array}$} \\
\hline \multirow[b]{2}{*}{$\begin{array}{l}\text { Grau de fragilidade dos tipos de } \\
\text { relevo e declividade }\end{array}$} & \multicolumn{5}{|c|}{ Grau de Fragilidade dos Solos } \\
\hline & $\begin{array}{l}\text { Muito baixo(1) } \\
\text { LEa29 }\end{array}$ & $\begin{array}{l}\text { Baixo (2) } \\
\text { PVe9 / } \\
\text { PVe5 }\end{array}$ & $\begin{array}{l}\text { Médio (3) } \\
\text { PVe8 / } \\
\text { PVe6 }\end{array}$ & $\begin{array}{l}\text { Alto (4) } \\
\text { Neossolo }\end{array}$ & $\begin{array}{l}\text { Muito alto } \\
\text { (5) } \\
\text { AQa5 /* }\end{array}$ \\
\hline $\begin{array}{l}\text { Muito baixo (1) } \\
\text { Topos planos (0 a } 10 \% \text { decl.) }\end{array}$ & 11 & 12 & 13 & - & - \\
\hline $\begin{array}{l}\text { Baixo ( } 2 \text { ) } \\
\text { Topos convexos (5 a } 10 \% \text { decl.) }\end{array}$ & - & 22 & 23 & - & - \\
\hline $\begin{array}{l}\text { Médio ( } 3 \text { ) } \\
\text { Vertente convexa retilíneas ( } 5 \text { a } \\
10 \% \text { decl.) }\end{array}$ & 31 & 32 & 33 & - & - \\
\hline $\begin{array}{l}\text { Alto (4) } \\
\text { Vertentes convexa côncava } \\
(>10 \% \text { decl.) }\end{array}$ & 41 & 42 & 43 & - & 45 \\
\hline $\begin{array}{l}\text { Muito alto (5) } \\
\text { Planície Fluvial ( } 0 \text { a } 5 \% \text { decl.) }\end{array}$ & - & - & - & - & 55 \\
\hline \multicolumn{6}{|c|}{$\begin{array}{l}\text { LEGENDA } \\
\text { (-) sem ocorrência na área de estudo. } \\
\text { LEa29 - Latossolo vermelho-escuro álico. } \\
\text { PVe9 - Argissolo vermelho - amarelo, eutrófico. } \\
\text { PVe8 - Argissolo vermelho - amarelo, eutróficoabruptico + concreções ferruginosas. } \\
\text { PVe6 - Argissolo vermelho - amarelo, eutrófico + concreções ferruginosas. } \\
\text { PVe5 - Argissolo vermelho - amarelo, eutrófico e distrófico. } \\
\text { Neossolo - Neossololitólico distrófico. } \\
\text { AQa5 - Areias quartzosas álicas / Gleissolos / * solos hidromórficos de meia encosta e fundo de vale. }\end{array}$} \\
\hline
\end{tabular}

Fonte: Os autores, 2015. 
A matriz de correlação a seguir (Quadro 9) representa as demais combinações dos ambientes ecodinâmicos de instabilidade emergente, ou seja, aqueles locais onde a paisagem foi intensamente antropizada ou transformada pelo cultivo agrícola temporário, permanente, pela silvicultura, entre outros, atribuindo diversos mosaicos heterogêneos. Para tanto, foram consideradas as diferentes compartimentações do relevo, tipos de solos e uso da terra / cobertura vegetal.

\section{Quadro 9 - Matriz de correlação entre uso da terra, relevo e solos para classificação das unidades ecodinâmicas de instabilidade emergente}

\begin{tabular}{|c|c|c|c|c|c|}
\hline \multicolumn{6}{|c|}{$\begin{array}{c}\text { MATRIZ DE CORRELACCÃO: USO DA TERRA X RELEVO X SOLOS } \\
\text { UNIDADES ECODINÂMICAS DE INSTABILIDADE EMERGENTE (INSTÁVEIS) } \\
\text { CONSTANTE - FATOR CLIMA - GRAU DE FRAGILIDADE (3) }\end{array}$} \\
\hline \multirow[b]{2}{*}{$\begin{array}{c}\text { Grau de fragilidade dos } \\
\text { solos + tipos de relevo e } \\
\text { declividade }\end{array}$} & \multicolumn{5}{|c|}{ Grau de fragilidade do uso da terra / cobertura vegetal } \\
\hline & $\begin{array}{l}\text { Muito baixo } \\
\text { (1) } \\
\text { Matas } \\
\text { naturais }\end{array}$ & $\begin{array}{l}\text { Baixo (2) } \\
\text { Capoeira / } \\
\text { palustre / } \\
\text { pousio }\end{array}$ & $\begin{array}{c}\text { Médio (3) } \\
\text { Silvicultura / } \\
\text { cultura } \\
\text { permanente / } \\
\text { cana }\end{array}$ & $\begin{array}{c}\text { Alto (4) } \\
\text { Cultura } \\
\text { temporária }\end{array}$ & $\begin{array}{l}\text { Muito Alto } \\
\text { (5) } \\
\text { Outros }\end{array}$ \\
\hline \multicolumn{6}{|l|}{ Muito baixo (1) } \\
\hline T.P. + LEa29 (11) & - & - & 311 & 411 & 511 \\
\hline \multicolumn{6}{|l|}{ Baixo (2) } \\
\hline T.P. + PVe9/PVe5 (12) & - & - & 312 & 412 & 512 \\
\hline T.C + LEa29 (21) & - & - & 321 & - & 521 \\
\hline T.C. + PVe9 / PVe5 (22) & - & - & 322 & 422 & 522 \\
\hline \multicolumn{6}{|l|}{ Médio (3) } \\
\hline V.C. R. + LEa29 (31) & - & - & 331 & 431 & 531 \\
\hline V.C. R.+ PVe9/PVe5 (32) & - & - & 332 & 432 & 532 \\
\hline V.C.R. + PVe8 / PVe6 (33) & - & - & 333 & - & 533 \\
\hline T.C. + PVe8 / PVe6 (23) & - & - & 323 & 423 & 523 \\
\hline T.P. + PVe8 / PVe6 (13) & - & - & 313 & - & 513 \\
\hline \multicolumn{6}{|l|}{ Alto (4) } \\
\hline V.C.C + LEa29 (41) & - & - & 341 & - & 541 \\
\hline V.C.C. + PVe9 / PVe5 (42) & - & - & 342 & 442 & 542 \\
\hline V.C.C. + PVe8 / PVe6 (43) & - & - & 343 & 443 & 543 \\
\hline V.C.C + Neossolo (44) & - & - & - & - & 544 \\
\hline V.C.R + Neossolo (34) & - & - & - & - & 534 \\
\hline T.C. + Neossolo (24) & - & - & - & - & - \\
\hline T.P. + Neossolo (14) & - & - & - & - & - \\
\hline \multicolumn{6}{|l|}{ Muito alto (5) } \\
\hline P.F + LEa29 (51) & - & - & - & - & - \\
\hline P.F + PVe9 / PVe5 (52) & - & - & - & - & - \\
\hline P.F. + PVe8 / PVe6 (53) & - & - & - & - & - \\
\hline P.F. + Neossolo (54) & - & - & - & - & - \\
\hline P.F. + AQa5 / * (55) & - & 255 & - & - & - \\
\hline V.C.C + AQa5 / * (45) & - & 245 & - & - & - \\
\hline V.C.R + AQa5 / * (35) & - & 235 & - & - & - \\
\hline T.C. + AQa5 /* (25) & - & - & - & - & - \\
\hline T.P. + AQa5 / * (15) & - & - & - & - & - \\
\hline \multicolumn{6}{|c|}{$\begin{array}{l}\text { LEGENDA: } \\
\text { (-) - Sem ocorrência. } \\
\text { C.A. - Colinas amplas ( } 0 \text { a } 10 \% \text { declividade) } \\
\text { C.M. - Colinas médias (5 a } 10 \% \text { declividade). } \\
\text { M.S. - Morros sedimentares ( } 5 \text { a } 10 \% \text { declividade). } \\
\text { M.A.E. - Morrotes alongados e espigões ( }>10 \% \text { declividade). } \\
\text { P.F. - Planície fluvial ( } 0 \text { a } 5 \% \text { declividade). }\end{array}$} \\
\hline
\end{tabular}

Fonte: Os autores, 2015. 
Assim, são apresentadas, sinteticamente, no quadro 10 as possíveis combinações numéricas que delimitam os polígonos da área de estudo, no qual o último dígito de cada grau de fragilidade representa a classificação atribuída anteriormente ao clima.

\section{Quadro 10 - Classificação numérica por grau de fragilidade das unidades ecodinâmicas de instabilidade potencial e emergente (possíveis combinações)}

\begin{tabular}{|c|c|c|c|c|c|c|c|c|c|}
\hline \multicolumn{10}{|c|}{$\begin{array}{l}\text { GRAUS DE FRAGILIDADE: CLASSIFICAÇÃO NUMÉRICA DOS POLÍGONOS } \\
\text { (POSSÍVEIS COMBINAÇÕES). }\end{array}$} \\
\hline \multicolumn{5}{|c|}{$\begin{array}{l}\text { Unidades ecodinâmicas de instabilidade } \\
\text { potencial (estável) }\end{array}$} & \multicolumn{5}{|c|}{$\begin{array}{l}\text { Unidades ecodinâmicas de instabilidade } \\
\text { emergente (instável) }\end{array}$} \\
\hline $\begin{array}{l}\text { Muito } \\
\text { baixo }\end{array}$ & Baixo & Médio & Alto & $\begin{array}{l}\text { Muito } \\
\text { alto }\end{array}$ & $\begin{array}{l}\text { Muito } \\
\text { baixo }\end{array}$ & Baixo & Médio & Alto & $\begin{array}{l}\text { Muito } \\
\text { alto }\end{array}$ \\
\hline 1113 & $\begin{array}{l}1123 \\
1223\end{array}$ & $\begin{array}{l}1133 \\
1233 \\
1313 \\
1323 \\
1333\end{array}$ & $\begin{array}{l}1413 \\
1423 \\
1433\end{array}$ & $\begin{array}{l}1453 \\
1553\end{array}$ & & & $\begin{array}{l}3113 \\
3123 \\
3133 \\
3213 \\
3223 \\
3233 \\
3313 \\
3323 \\
3333\end{array}$ & $\begin{array}{l}3413 \\
3423 \\
3433 \\
4113 \\
4123 \\
4223 \\
4233 \\
4313 \\
4323 \\
4423 \\
4433\end{array}$ & $\begin{array}{l}2353 \\
2453 \\
2553 \\
5113 \\
5123 \\
5133 \\
5213 \\
5223 \\
5233 \\
5313 \\
5323 \\
5333 \\
5343 \\
5413 \\
5423 \\
5433 \\
5443\end{array}$ \\
\hline
\end{tabular}

Fonte: Os autores, 2015.

Observa-se no quadro 10 a existência de uma quantidade significativa de unidades com instabilidade emergente "muito alta". Isto está relacionado às condições em que os ambientes analisados se encontram e que foram de alguma forma alterados por atividades antrópicas.

No tocante aos ambientes ecodinâmicos de instabilidade potencial, a vegetação existente é capaz de manter a estabilidade morfogenética e, em determinadas situações, apresentam-se como locais sensíveis a intervenções antrópicas, podendo passar de estáveis para intergrades, retornar para estável novamente ou avançar rapidamente para instável. Além disso, são ambientes que na sua grande maioria encontram-se preservados, portanto, a instalação de aterro sanitário nesses ambientes torna-se inviável.

Ao interferir nos ambientes que ainda permanecem estáveis, com, por exemplo, a supressão da vegetação, alterações de fluxos de energia e matéria dos sistemas são inevitáveis, visto que diretamente ligados ao equilíbrio dinâmico, por isso devem ser, necessariamente, protegidos.

Desta forma, foram identificados locais onde a vegetação arbórea mantém a estabilidade das encostas declivosas, sustentando o equilíbrio dinâmico entre os flu- 
xos de matéria e energia e controlando consequentemente os processos erosivos. Importante ressaltar que além do caráter de preservação, existem, em concomitância, alguns fatores geotécnicos que impedem a instalação de aterros sanitários em locais com declividade elevada, solo raso, áreas com surgência do freático e próximo a outros recursos hídricos.

A figura 1 a seguir representa as unidades de fragilidade ambiental do município de Anhumas, obtida através da integração dos elementos da paisagem já mencionados. Reforça-se, assim, a importância da análise integrada, visto que os elementos da paisagem exercem constante influência entre si.

A análise do presente trabalho concentra-se apenas nas unidades de instabilidade emergente (Quadro 11) por serem ambientes com fragilidade ambiental elevada e, consequentemente, inadequados à instalação de aterros sanitários. Nas demais unidades, ou seja, as de instabilidade potencial, a vegetação existente exerce sua função ecológica e, portanto, devem ser mantidas e preservadas, desconsiderando qualquer possibilidade viável de instalação de aterro sanitário nestas áreas.

Conforme a carta de fragilidade ambiental apresentada na Figura 1, observase que no município de Anhumas existem locais com fragilidade variando de médio a muito alto, os quais restringem a instalação de aterros sanitários em função de suas características de instabilidade emergente, como já mencionado anteriormente.

Entretanto, na medida em que essas áreas são recuperadas no aspecto de vegetação arbórea nativa, a tendência à existência de ambientes de instabilidade emergente tenderá a diminuir, visto que tais locais são fortemente influenciados pela capacidade da vegetação em sustentar o equilíbrio dinâmico na paisagem. 


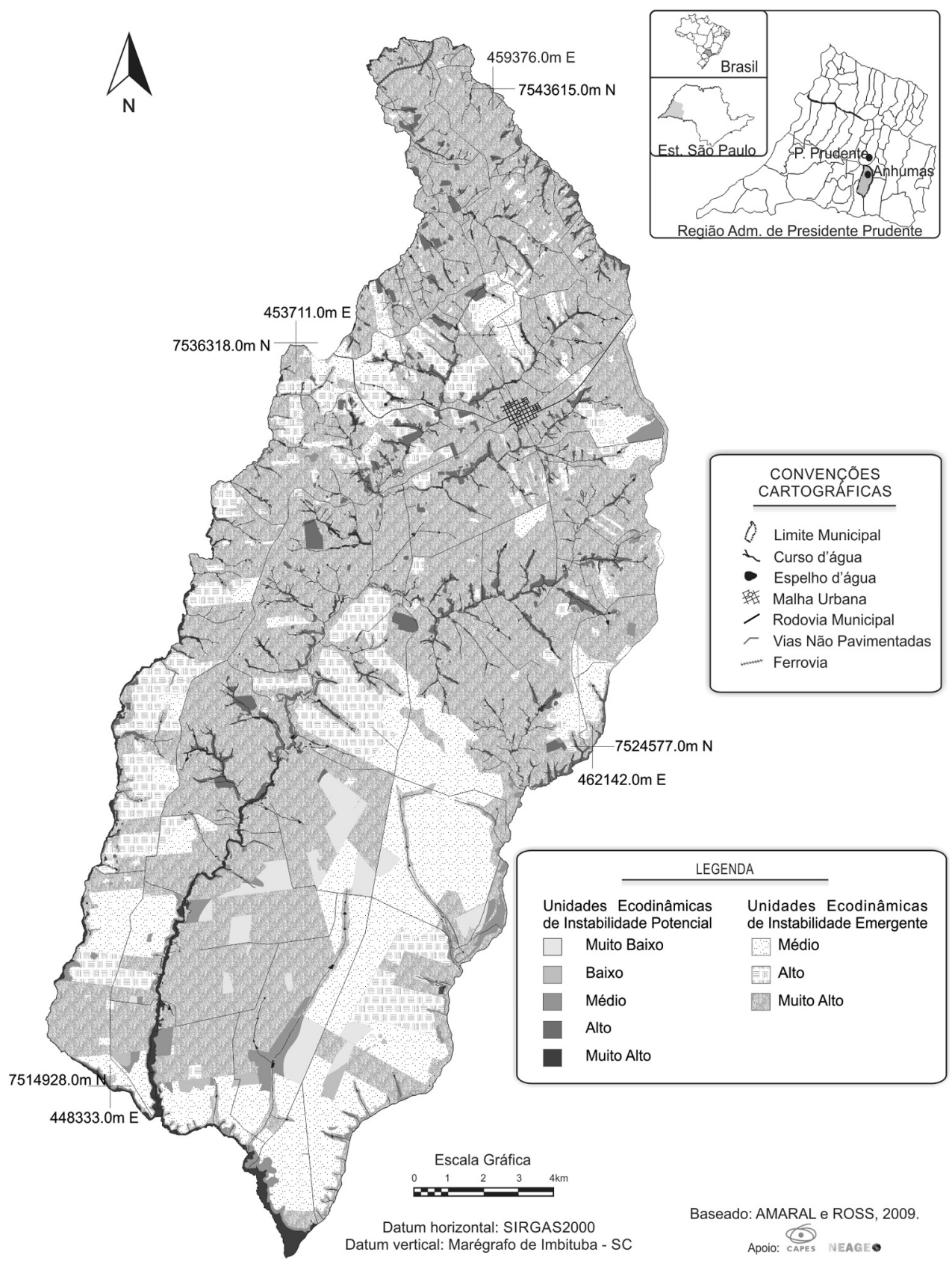

Figura 1 - Carta de fragilidade conforme a teoria da ecodinâmica de Tricart (1977)

Fonte: Os autores, 2015. 


\section{Quadro 11 - Síntese das unidades de instabilidade emergente}

\begin{tabular}{|c|c|}
\hline \multicolumn{2}{|r|}{ UNIDADE ECODINÂMICA DE INSTABILIDADE EMERGENTE } \\
\hline \multirow{4}{*}{ 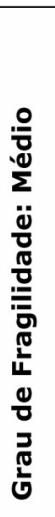 } & Descrição da Unidade \\
\hline & $\begin{array}{l}\text { Unidade caracterizada por extensas áreas de cultivo de cana-de-açúcar e } \\
\text { áreas restritas de cultura permanente e silvicultura. O relevo de topos } \\
\text { planos contribui para o manejo mecanizado da cana-de-açúcar e } \\
\text { consequentemente para a expressividade espacial dessa cultura. Em alguns } \\
\text { setores o plantio da cana avança sobre as vertentes retilíneas em direção } \\
\text { aos fundos de vale dos principais cursos d'água do município (Ribeirão } \\
\text { Anhumas e Córrego da Onça). Quando em Argissolos e em interflúvios de } \\
\text { topos convexos, os polígonos desta unidade tornam-se reduzidos }\end{array}$ \\
\hline & Atributos de fragilidade / aspectos ambientais relacionados \\
\hline & $\begin{array}{l}\text { Necessidade de aplicação de agrotóxicos. Possibilidade de contaminação dos } \\
\text { recursos hídricos superficiais e subterrâneo. Baixa ou nula densidade de } \\
\text { vegetação arbórea nativa. Eventual sanilização dos solos. A retirada dos } \\
\text { terraços agrícolas pode desencadear processos erosivos, os quais são } \\
\text { comuns nessa região devido à excessiva fragilidade do solo }\end{array}$ \\
\hline \multirow{4}{*}{ 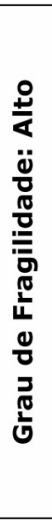 } & \\
\hline & $\begin{array}{l}\text { Unidade caracterizada por extensas áreas de cultivo de cana-de-açúcar e } \\
\text { áreas restritas de cultura permanente, temporária e silvicultura, } \\
\text { especialmente quando situada sobre relevo de topos planos ou retilíneo e } \\
\text { Latossolo. Prepondera o relevo de vertente côncava convexa e Argissolos, } \\
\text { sendo os mosaicos de culturas permanentes, temporárias e silvicultura de } \\
\text { tamanhos inferiores aos da cana. Em alguns setores o plantio da cana } \\
\text { avança em direção aos fundos de vale do Ribeirão Anhumas, Córrego do } \\
\text { São Pedro, Córrego do Cambuí e Córrego da Onça }\end{array}$ \\
\hline & lacionados \\
\hline & $\begin{array}{l}\text { Necessidade de aplicação de agrotóxicos. Possibilidade de contaminação dos } \\
\text { recursos hídricos superficiais e subterrâneo. Baixa ou nula densidade de } \\
\text { vegetação arbórea nativa. Eventual sanilização dos solos. A retirada dos } \\
\text { terraços agrícolas pode desencadear processos erosivos, os quais são } \\
\text { comuns nessa região devido a excessiva fragilidade do solo }\end{array}$ \\
\hline \multirow{4}{*}{ 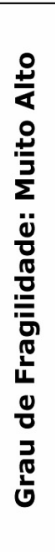 } & \\
\hline & $\begin{array}{l}\text { Extensas áreas de pastagem e solos em preparo para plantio, além de } \\
\text { setores restritos com vegetação palustre e pousio. Esta unidade é a mais } \\
\text { abrangente do município, sendo de comum ocorrência em planícies fluviais, } \\
\text { vertentes convexas retilíneas, vertentes côncavas convexas, topos } \\
\text { convexos, topos planos, em solos Latossolo, Argissolos, solos hidromórficos } \\
\text { e Neossolos litólicos. Em alguns setores das unidades de mapeamento KaIV } \\
\text { e KaV, ocorrem também feições hidrogeológicas refletidas na superfície do } \\
\text { terreno (lençóis suspensos) associadas à alta declividade, além de } \\
\text { processos erosivos avançados e outros já obliterados }\end{array}$ \\
\hline & Atributos de fragilidade / aspectos ambientais relacionados \\
\hline & $\begin{array}{l}\text { Baixa biodiversidade. Ausência de matas ciliares. Baixa ou nula densidade } \\
\text { de vegetação arbórea nativa. A consequente substituição da cobertura } \\
\text { vegetal arbórea pela gramínea de pastagem muitas vezes é responsável } \\
\text { pelo desencadeamento de diversos processos erosivos, os quais são comuns } \\
\text { nessa região devido à excessiva fragilidade do solo. }\end{array}$ \\
\hline
\end{tabular}

Fonte: Os autores, 2015. 


\section{CONCLUSÕES}

A proposta de análise ecodinâmica da paisagem aplicada a escolha de área para aterros sanitários, associada à espacialização cartográfica destas informações, se mostrou pertinente ${ }_{+}$ao passo que contribui na quantificação e avaliação das combinações dos elementos da paisagem, naturais e antrópicos, que compõe as unidades ecodinâmica nas distintas categorias de instabilidade potencial e emergente. A referida representação facilitou a interpretação da problemática na escolha de áreas para aterros sanitários, em bacia sedimentares, na elaboração do diagnóstico ambiental e de apontamentos prognósticos.

Embora a fragilidade natural do município, pelas formações geológicas e pedológicas, predominantemente arenosas, esteja representada nas unidades ecodinâmicas de instabilidade potencial (estável) e instabilidade emergente (instável), apontadas no Quadro 10, é possível verificar que a instabilidade potencial, em menor número de unidade de paisagem e em sua distribuição espacial, conjectura o grau de ocupação e degradação do município de Anhumas, enquanto que a instabilidade emergente, além de traduzir o grau de ocupação, reflete as características desfavoráveis do meio físico do município de Anhumas ao atender aos aspectos geotécnicos necessários à instalação de aterros sanitários. Neste sentido, observa-se que aproximadamente $80 \%$ do município apresentam um grau de fragilidade muito alto e nenhuma unidade de baixo a muito baixo grau de instabilidade emergente, o que os torna impróprio a receber aterros de resíduos sólidos sem os devidos critérios de um aterro sanitário "senso stricto". Isto era de se esperar em bacia sedimentares sobre rochas porosas de alta permeabilidade do solo, já que esse fator torna o local extremamente restrito à construção de aterros de resíduos.

Além de destacar a fragilidade natural das unidades ecodinâmica de instabilidade potencial e emergente, através das características do meio físico, de acordo com os graus atribuídos à cada classe de fragilidade e de terrenos que podem ser destinados ao uso antrópico, os dados apontam que as áreas de maior fragilidade à instalação de aterros de resíduos, apresentam também fragilidade aos processos morfodinâmicos do solo, o que, como consequência, concentra dezenas de feições erosivas lineares, laminares e de mudanças na rede de drenagem destacadas no assoreamento dos corpos d'água.

Nesse sentido, os setores das unidades de mapeamento $\mathrm{Ka}_{\mathrm{IV}}$ e $\mathrm{Ka}_{\mathrm{V}}$ (ALMEIDA et al, 1980), distribuídas pelo centro, norte e oeste do município, apresentam graus de fragilidade muito alto, determinado pelas suas características litológicas, estruturais, de relevo, pedológicas, de declividade, de uso da terra e cobertura vegetal, que se inter-relacionam em sua dinâmica ambiental, propiciando a análise dos condicionantes da paisagem de modo integrado e a identificação da fragilidade natural de cada meio.

Apesar dos terrenos do município apresentarem graus de fragilidades muito alto, alto e médio, uma alteração na lógica de uso dos recursos naturais, promovida mediante práticas de conservação e preservação, que destinam faixas de proteção e retenção dos líquidos contaminantes do solo e da água, assim como a recuperação do potencial geoecológico do município, é imprescindível, visto que poucos são os setores de unidades ecodinâmicas de instabilidade potencial (estável). É importante destacar essa alternativa, pois recentes pesquisas demonstraram existir produção, em excesso, de resíduos sólidos e áreas em escassez para a implantação adequada de aterros. Outro aspecto a ser considerado, além das características ecodinâmicas do município, é a implantação de aterros sanitários que não ignorem a possibilidade e necessidade de estabelecer usos mais sustentáveis, mesmo em situações que evidenciam médio grau de fragilidade, além de monitoramento constante das atividades no aterro sanitário. 
Este estudo referente às problemáticas para a disposição final ambientalmente adequada dos resíduos sólidos demonstrou, mais uma vez, por intermédio de suas análises, a imprescindibilidade em interconectar diferentes saberes, como os da ecodinâmica dos ambientes, das dinâmicas da paisagem, da geografia, da pedogênese, da geoecologia das paisagens, na morfogênese, entre outros. Trata-se da interdisciplinaridade como exigência da demanda externa e da necessária e complexa elaboração do diagnóstico ambiental contendo apontamentos prognósticos.

É próprio do trabalho interdisciplinar e do pensamento complexo constituir-se numa via propositiva de diálogo e de discussão entre diversos saberes. No centro desses debates, encontra-se a demanda externa advinda da busca de um local adequado para a disposição de resíduos sólidos no município de Anhumas (SP), associada à teoria da ecodinâmica dos ambientes naturais de Tricart (1977). A referida interdisciplinaridade contribuiu severamente para aprimorar a compreensão dos aspectos de fragilidade ambiental no município de Anhumas, corroborando para a me-

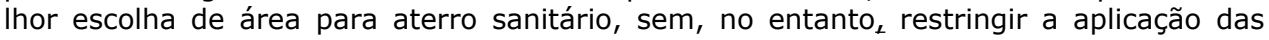
demais técnicas usualmente empregadas aos estudos diagnósticos para aterros sanitários.

\section{REFERÊNCIAS}

ALMEIDA et.al. "Geologia do Oeste Paulista e áreas fronteiriças dos estados de Mato Grosso do Sul e Paraná". In: SBG, CONGRESSO BRASILEIRO DE GEOLOGIA, 31, Camboriú, Anais... v. 5, p. 2799-2812, 1980.

ALVES, A. O. Criando mapa de declividade a partir de dados SRTM (tutorial). Comunidade Virtual Spring, 2008. Disponível em: <www.comunidadespring.com.br>. Acesso em: 11 out. 2013.

AMARAL, R.; ROSS, J.L.S. As unidades ecodinâmicas na análise da fragilidade ambiental do parque estadual do Morro do Diabo e entorno, Teodoro Sampaio/SP. GEOUSP Espaço e Tempo. São Paulo, n. 26, p. 59 - 78, 2009.

BOIN, M. N. Chuvas e erosões no oeste paulista: uma análise climatológica aplicada. 2000. 264f. Tese (Doutorado em Geociências) - I. G. C. E. UNESP, Rio Claro.

BOSCOV, M. E. G.. Geotecnia ambiental. São Paulo: Oficina de Textos, 2012.

EMBRAPA, Empresa Brasileira de Pesquisa Agropecuária. Mapa pedológico do estado de São Paulo. Escala: 1:500.000. São Paulo, 1999.

IPT, Instituto de Pesquisas Tecnológicas do Estado de São Paulo. Mapa geológico do estado de São Paulo, 1:500.000. São Paulo: IPT, v 2, 1981a.

IPT, Instituto de Pesquisas Tecnológicas do Estado de São Paulo. Mapa geomorfológico do estado de São Paulo, 1:1.000.000. São Paulo: IPT, v. 2, 1981b.

$L E A L, A$. C. Meio ambiente e urbanização na microbacia do Areia Branca Campinas, SP. 152p. Dissertação (Mestrado em Geociência e Meio Ambiente), Instituto de Geociências e Ciências Exatas, Universidade Estadual Paulista, Rio Claro, 1995.

LEITE, J. C. e ZUQUETTE, L. V. Atributos fundamentais à elaboração da carta de susceptibilidade à contaminação e poluição das águas superficiais. In: CONGRESSO BRASILEIRO DE GEOLOGIA DE ENGENHARIA. Anais... Rio de Janeiro: ABGE, p. 1771823, 1996. 
LEITE, J. C. Metodologia para elaboração da carta de susceptibilidade à contaminação e poluição das águas superficiais. 1995. 192f. Dissertação (Mestrado em Geotecnia) - Departamento de Geotecnia, Escola de Engenharia de São Carlos, Universidade de São Paulo. São Carlos.

MATEO-RODRIGUEZ, J.M.; SILVA, E. V.; CAVALCANTI, A. O. B. Geoecologia das paisagens: uma visão geossistêmica da análise ambiental. Fortaleza: Editora UFC, 2004.

MONTAÑO, M.; RANIERI, V. E. L.; SCHALCH, V. FONTES, A. T.; CASTRO, M. C. A. A.; SOUZA, M. P. Integração de critérios técnicos, ambientais e sociais em estudos de alternativas locacionais para implantação de aterro sanitário. EngSanitAmbient, v. 17 , n. 1, p. 61-70, 2012.

NUNES, J. O. R. Uma contribuição metodológica ao estudo da dinâmica da paisagem aplicada à escolha de áreas para construção de aterro sanitário em Presidente Prudente. 2002. 211 f. Tese (Doutorado em Geografia) - Faculdade de Ciência e Tecnologia, Universidade Estadual Paulista. Presidente Prudente.

OLIVEIRA, M. H. Avaliação da qualidade das águas superficiais da microbacia do córrego do Amargoso Taciba (SP). 2002. 88f. Tese (Doutorado em Geografia). F. C. T. UNESP. Presidente Prudente - SP.

OLIVEIRA, R. C. ; BOIN, M. N.; PEREIRA, M. H. Disposição inadequada de resíduos sólidos urbanos e a contaminação dos recursos hídricos: o caso do município de Taciba - SP. CONGRESSO NACIONAL DE MEIO AMBIENTE DE POÇOS DE CALDAS, 11. Anais... Poços de Caldas: IFMG, 2014.

OLIVEIRA, R. C. Avaliação do potencial poluidor de aterro em vala: analogia entre o aterro em vala e o lixão desativado de Taciba - SP. 2012. 73 f. Trabalho de conclusão de cursos (Engenharia Ambiental) - Faculdade de Engenharia e Arquitetura, Universidade do Oeste Paulista - UNOESTE, Presidente Prudente.

OLIVEIRA, R. C. Escolha de área para aterro sanitário em meios porosos: 0 caso do município de Anhumas - SP. 2015. 185f. Dissertação (Mestrado em Meio Ambiente e Desenvolvimento Regional). Universidade do Oeste Paulista - UNOESTE, Presidente Prudente.

ROSS, J. L. S. Análise empírica da fragilidade dos ambientes naturais e antropizados. Revista do Departamento de Geografia, São Paulo, n. 8, p. 63-73, 1994.

SANTOS, R. F. Planejamento ambiental: teoria e prática. São Paulo: Oficina de textos, 2004.

TRESSOLDI, M.; CONSONI, J.A. Disposição de resíduos. In: Geologia de Engenharia. São Paulo: Associação Brasileira de Geologia de Engenharia, 1998.

TRICART, J. Ecodinâmica. Rio de Janeiro: IBGE/SUPREN, 1977.

ZUQUETTE, L. V.; PEJON, O. J.; SINELI, O. Methodology for specific engineering geological mapping for selection of sites for waste disposal. In: INTERNATIONAL IAEG CONGRESS, 7, Rotterdam. Anais... Balkerna, Rotterdam, 1994. p. 2481-2489.

Recebido em setembro de 2015 Revisado em julho de 2016 Aceito em agosto de 2016 